\title{
Morphological Characterization and Molecular Verification of a Fertile Haploid Pummelo (Citrus grandis Osbeck)
}

\author{
Masaki Yahata \\ The United Graduate School of Agricultural Sciences, Kagoshima University, 1-21-24 Korimoto, \\ Kagoshima-shi, Kagoshima 890-0065, Japan \\ Seiichi Harusaki and Haruki Komatsu ${ }^{1}$ \\ School of Agriculture, Kyusyu Tokai University, Kawayo, Choyo-son, Aso-gun, Kumamoto 869-1404, \\ Japan
}

Kayo Takami, Hisato Kunitake, Tsutomu Yabuya, and Kensuke Yamashita

Faculty of Agriculture, University of Miyazaki, 1-1 Gakuenkibanadainishi, Miyazaki-shi, Miyazaki 889-2192, Japan

\author{
Pichit Toolapong \\ Faculty of Agriculture, Maejo University, Chiang Mai, Thailand 50290
}

ADDITIONAL INDEX WORDS. gynogenesis, flow cytometry, RAPD, unreduced pollen grains, pollen fertility

\begin{abstract}
The morphological characteristics and reproductive potential of a haploid plant obtained from the cross between 'Banpeiyu' pummelo (Citrus grandis) and 'Ruby Red' grapefruit ( $C$. paradisi Macf.) were investigated. The haploid was confirmed to be derived from female gamete of 'Banpeiyu' pummelo by isozyme and random amplified polymorphic DNA (RAPD) analysis. Flow cytometry analysis revealed that the haploidy was maintained in several tissues and organs of this plant. It also had the typical morphology of a haploid, such as small leaves and flowers, and had slightly fertile pollen grains. Furthermore, diploid progenies were obtained from the cross between 'Kiyomi' tangor and the haploid. The hybridity of these seedlings was confirmed by assessment of the leaf characteristics and RAPD analysis. These results suggest that this haploid produced fertile unreduced pollen grains $(n=9)$.
\end{abstract}

The importance of haploids for plant breeding and genetic analysis is well recognized (Bajaj, 1990; Ochatt and Zhang, 1996). This is especially the case for woody species, which are generally characterized by a long reproductive cycle, a high degree of heterozygosity, a large canopy size, and self-incompatibility. For these same reasons, genetic improvement by conventional methods is time-consuming and limited by the required space for field cultivation. Since the 1960s, approaches to chromosome manipulation, such as haploid induction and chromosome doubling have offered novel new possibilities for both the genetic study and the improvement of these plants. Several haploid induction methods such as in vitro gynogenesis and in situ parthenogenesis, induced by pollination with irradiated pollen and followed by the application of new anti-microtubule herbicides for chromosome doubling, have been described in the literature (Ochatt and Zhang, 1996; Wan et al., 1989, 1991; Wan and Widholm, 1995).

Karasawa (1971) first reported haploid production from the seeds of $C$. natsudaidai Hayata that had been exposed to X-ray

Received for publication 17 Feb. 2004. Accepted for publication 13 June 2004. The authors are grateful to Dr. Masahiro Mii of Faculty of Horticulture, Chiba Univ., for his advice and critical reading of this manuscript. The authors thank Mr. Akira Isobe of the Fruit Tree Research Institute, Kumamoto Prefectural Agricultural Research Center, for kindly providing 'Banpeiyu' pummelo and 'Ruby Red' grapefruit. This research was supported by Diet and Cancer Prevention: Exploring Research Technology, Miyazaki Prefecture Collaboration of Regional Entities for the Advancement of Technological Excellence, JST and Grant-in-Aid (no. 14560025) from the Ministry of Education, Science, Sports and Culture of Japan.

${ }^{1}$ Corresponding author: e-mail address hkomatsu@ktmail.ktokai-u.ac.jp irradiation. Haploids have been produced using anther culture in trifoliate orange [Poncirus trifoliata (L.) Raf.] (Hidaka et al., 1979), calamondin (C. madurensis Lour.) (Chen et al., 1980), and clementine (C. clementina Hort. ex Tanaka) (Germana and Chiancone, 2003). Oiyama and Kobayashi (1993) obtained haploid seedlings from clementine and 'Lee' $[C$. clementina $\times(C$. reticulata Blanco $\times$ C. paradisi)], using the pollen from a triploid progeny that was produced by the cross between diploid 'Naruto' (C. medioglobosa Hort. ex Tanaka) and tetraploid 'Funadoko' (C. funadoko Hort. ex Tanaka). Germana and Chiancone (2001) also induced haploid clementine plantlets by in vitro pollination with the pollen grains of 'Oroblanco' $(C$. grandis $\times C$. paradisi), a triploid grapefruit cultivar. However, these haploids were very weak, and they grew more slowly than diploid plants. Therefore, no flowering of haploids in Citrus L. species has ever been reported, and the reproductive potential has not yet been determined.

Toolapong et al. (1996) selected a haploid progeny from among small seed-derived seedlings obtained from the cross between 'Banpeiyu' pummelo and 'Ruby Red' grapefruit. This haploid showed dwarf growth behavior and rosette morphology, similar to that of haploids previously obtained from other cross combination methods. However, it grew very well when it was grafted onto trifoliate orange (Fig. 1A). Seven years after germination this haploid had many flowers for the first time (Fig. 1B).

The objectives of the present study were as follows: 1) to identify the origin of this haploid using isozyme and RAPD techniques, 2) to confirm the stability of the ploidy level of the haploid in several tissues and organs by flow cytometry, and 3) to compare the morphological characteristics and pollen fertility of 


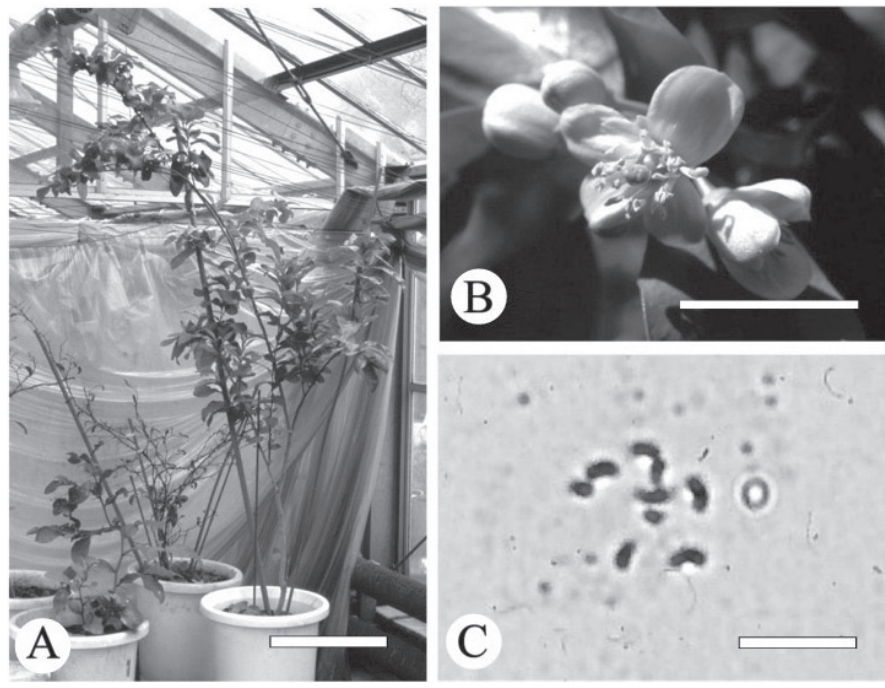

Fig. 1. The haploid from among small seed-derived seedlings obtained from the cross between 'Banpeiyu' pummelo and 'Ruby Red' grapefruit; $\mathbf{A}=7$-yearold haploid tree $(\mathrm{bar}=30 \mathrm{~cm}), \mathbf{B}=$ flowers of the haploid $(\mathrm{bar}=3 \mathrm{~cm}), \mathbf{C}=$ chromosomes of young leaf cells $(2 \mathrm{n}=\mathrm{X}=9$, bar $=10 \mu \mathrm{m})$.

the haploid and 'Banpeiyu' pummelo. Furthermore, we evaluated the reproductive potential of the haploid as a male or a female parent by crossing it with diploid citrus cultivars.

\section{Materials and Methods}

\section{Plant materials}

A haploid plant obtained from the cross between 'Banpeiyu' pummelo and 'Ruby Red' grapefruit (Toolapong et al., 1996) was used in the present study. This haploid was grafted onto trifoliate orange, and maintained for 7 years in the greenhouse at School of Agriculture of Kyushu Tokai Univ. Approximately 10-year-old 'Banpeiyu' pummelo and 'Ruby Red' grapefruit, both grown in the Fruit Tree Research Institute at Kumamoto Prefectural Agricultural Research Center, were used as controls.

\section{Origin of haploid}

IsOzYME ANALYSIS. Enzymes were extracted from young expanding leaves and electrophoresed in $7 \%$ polyacrylamide gels according to the method of Hirai et al. (1986). The following enzymes were analyzed: glutamate oxaloacetate transaminase (GOT,E.C.2.6.1.1), isocitrate dehydrogenase(IDH, E.C.1.1.1.41), 6-phoshogluconate dehydrogenase (6-PDH, E.C.1.1.1.44), shikimic acid dehydrogenase (SADH, E.C.1.1.1.25), diaphorase (DIA, E.C.1.6.4.3), phosphoglucomutase (PGM, E.C.2.7.5.1), malic enzyme (ME, E.C.1.1.1.40), malate dehydrogenase (MDH, E.C.1.1.1.37), and phosphoglucoisomerase (PGI, E.C.5.3.1.9).

RAPD ANALYSIS. Total DNA was extracted from young leaves of 'Banpeiyu' pummelo, 'Ruby Red' grapefruit, and the haploid, according to the method of Doyle and Doyle (1987). RAPD analysis was performed by the modified method of Williams et al. (1990). The reaction mixtures $(25 \mu \mathrm{L})$ contained $10 \mathrm{~mm}$ Tris$\mathrm{HCl}, \mathrm{pH} 8.9,80 \mathrm{~mm} \mathrm{KCl}, 1.5 \mathrm{~mm} \mathrm{MgCl}_{2}, 100 \mu \mathrm{M}$ each dNTPs, $0.3 \mu \mathrm{M}$ primer, 2.5 units (U) Tth Taq DNA polymerase, and 10 ng of genomic DNA. Reactions were carried out by repeating 45 cycles of the following thermal treatments: $94{ }^{\circ} \mathrm{C}$ for $30 \mathrm{~s}, 37^{\circ} \mathrm{C}$ for $2 \mathrm{~min}$, and $72^{\circ} \mathrm{C}$ for $3 \mathrm{~min}$, using an ASTEC Program Control System PC-700 (ASTEC Co., Fukuoka, Japan). The following primers were used: OPA8, OPA15, OPB8, OPB12, OPB16,
OPB20, OPC2, OPD7, OPD8, OPF3, OPF5, OPF6, OPF14, and OPF16 in Operon random 10-mer primers, (Operon Technology, Alameda, Calif.). The reaction products were electrophoresed on $1.3 \%$ agarose gels containing $0.5 \mu \mathrm{g} \cdot \mathrm{mL}^{-1}$ ethidium bromide and the products subsequently photographed under ultraviolet light $(360 \mathrm{~nm})$. For each combination of samples and primers, PCR was carried out twice, and only the stable polymorphisms were taken into account.

\section{Confirmation of ploidy level}

Chromosome observation. Young leaves $(\approx 3-5 \mathrm{~mm}$ long $)$ were excised from the haploid, immersed in $2 \mathrm{~mm} 8$-hydroxyquinoline for $6 \mathrm{~h}$ at $4{ }^{\circ} \mathrm{C}$, and fixed in a mixed solution of ethanol and acetic acid $(3: 1)$ for $12 \mathrm{~h}$ at $4{ }^{\circ} \mathrm{C}$. Enzymatic maceration and air drying were performed according to the method of Fukui (1996) with some modifications. The young leaves were washed in distilled water to remove the fixative and they were then macerated in an enzyme mixture containing 2\% (w/v) Cellulase Onozuka RS (Yakult Pharmaceutical Ind. Co., Tokyo), $1 \%$ (w/v) Macerozyme R-200 (Yakult Pharmaceutical), 0.3\% (w/v) Pectolyase Y-23 (Kyowa Chemical Products Co., Osaka, Japan), and $200 \mathrm{~mm}$ EDTA at $37^{\circ} \mathrm{C}$ for $40 \mathrm{~min}$. The chromosomes were stained with $2 \%$ Giemsa solution (Merck KGaA, Darmstadt, Germany) in 1/30 phosphate buffer ( $\mathrm{pH}$ 6.8) for $30 \mathrm{~min}$, rinsed with distilled water, air-dried, and observed under an optical microscope.

FLOWCYTOMETRY. Young leaves, sepals, petals, and filaments of $\approx 1-\mathrm{cm}^{2}$ segments were collected from the haploid and 'Banpeiyu' pummelo plants and the segments were chopped with a razor blade. These samples were treated for $5 \mathrm{~min}$ in $1 \mathrm{~mL}$ buffer solution containing $1 \%$ (v/v) Triton X-100, 140 mm mercaptoethanol, $50 \mathrm{~mm} \mathrm{Na}_{2} \mathrm{SO}_{3}$, and $50 \mathrm{~mm}$ Tris- $\mathrm{HCl}$ at $\mathrm{pH} 7.5$, according to the preparation method of Harusaki et al. (2000). Crude samples were filtered through a Miracloth (Merck KGaA) and were stained with $25 \mu \mathrm{g} \cdot \mathrm{L}^{-1}$ propidium iodide (PI). The relative fluorescence of the total DNA was measured for each nucleus with a Flow Cytometry System (EPICS XL; Beckman Coulter, Fullerton, Calif.) equipped with an argon laser (488 nm, $15 \mathrm{~mW}$ ).

\section{Morphological characteristics}

Several morphological characteristics of the haploid and 'Banpeiyu' pummelo were investigated. The size of the leaf blades and wing leaves as well as leaf weight and the size of the stomata of fully expanded leaves were measured. The morphological characteristics of flowers in full bloom (e.g., diameter, overall size, number of petals, number of stamens and ovules, size of pistils, pollen size, and number of pollen grains per anther) were measured using 10 samples. For the micromorphological observations, dried pollen grains were sputter-coated with gold using an ion-coater (IB-3; EIKO Engineering Co., Tokyo) followed by scanning electron microscopy (SEM) (ALPHA-30A; ABT Co., Tokyo).

\section{Pollen fertility}

The haploid and 'Banpeiyu' pummelo samples were used for testing stainability and for in vitro germination of the pollen grains. Pollen stainability was estimated by staining the samples with $1 \%$ acetocarmine after squashing nearly mature anthers on a slide glass. In vitro germination of the pollen grains was performed on microscope slides covered with a 2-mm layer of $1 \%$ (w/v) agar medium containing 10\% sucrose. Five stamens, each from different flowers, were rubbed on the agar medium, and the slides were then incubated for $10 \mathrm{~h}$ in a moistened chamber at $25^{\circ} \mathrm{C}$ in the dark. One thousand pollen grains were observed 


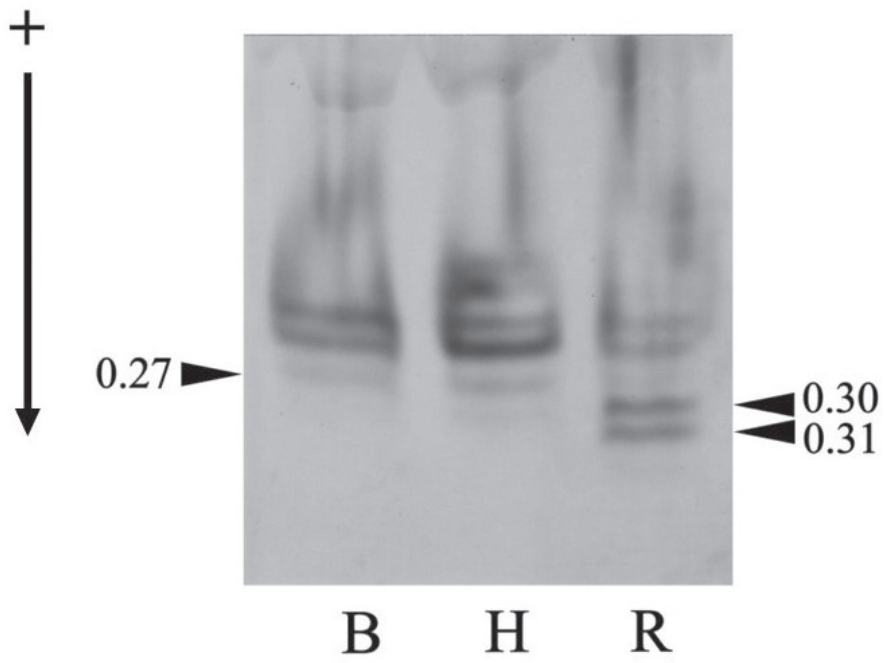

Fig. 2. Zymogram patterns of SADH in 'Banpeiyu' pummelo (B), the haploid $(\mathrm{H})$, and 'Ruby Red' grapefruit (R).

for each sample. Furthermore, the diameter of the pollen grains stained by $1 \%$ acetocarmine was measured.

\section{Crossing for evaluation of the reproductive potential of male and female gametes}

A monoembryonic diploid cultivar of 'Kiyomi' tangor $(C$. unshiu Marc. $\times$ C. sinensis Osbeck) was used as the seed parent and 'Kitou-Yuzu' ( $C$. junos Hort. ex Tanaka) was used as the pollen parent for the investigation of the reproductive potential of male and female gametes of the haploid, respectively. The flowers were pollinated immediately after emasculation and covered with paraffin paper bags. Seeds were collected from each fruit of the crosses at maturity; the seeds were then placed on moistened filter paper and maintained at $25^{\circ} \mathrm{C}$. After germination, ploidy analysis of the seedlings was performed by flow cytometry and chromosome observation. The hybridity of the seedlings was confirmed by using RAPD analysis, according to the methods described above.

\section{Results and Discussion}

Differences between 'Banpeiyu' pummelo and 'Ruby Red' grapefruit zymograms were observed in two enzymes, SADH and MDH, among all of the bands observed and all of the enzymes tested. Regarding SADH, the zymograms of the haploid showed banding patterns similar to those of 'Banpeiyu' pummelo, i.e., 'Ruby Red' grapefruit had two specific bands with relative mobility $(\mathrm{Rm})$ values of 0.30 and 0.31 , while the specific band of the haploid and 'Banpeiyu' pummelo had an Rm value of 0.27 (Fig. 2). In the case of $\mathrm{MDH}$, the haploid also had the same banding patterns as those of

Fig. 3. Random amplified polymorphic DNA (RAPD) analysis on 'Banpeiyu' pummelo (B), the haploid $(\mathrm{H})$, and 'Ruby Red' grapefruit $(\mathrm{R})$. Arrows indicate the bands specific to each parent.

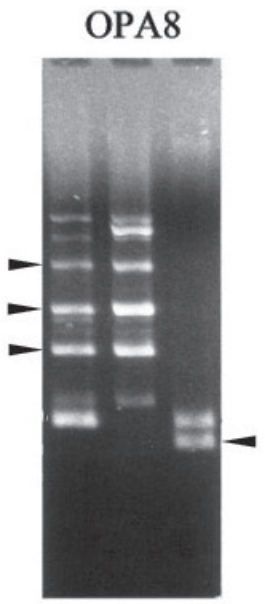

B $\quad \mathrm{H} \quad \mathrm{R}$

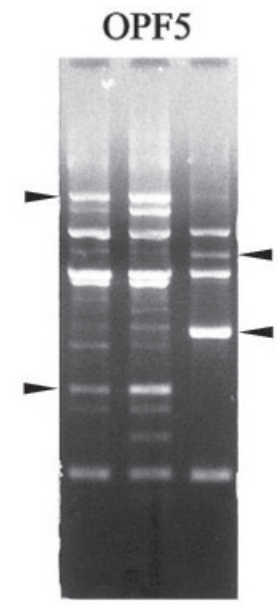

B $\mathrm{H} \quad \mathrm{R}$
'Banpeiyu' pummelo (data not shown). The RAPD analysis revealed amplifications of DNA were confirmed in all primers. The haploid was found to have almost the same banding patterns as those of 'Banpeiyu' pummelo in four primers of OPA8, OPF5, OPF6, and OPF14; however, several novel bands were observed in the case of the haploid (Fig. 3). On the other hand, no unique bands from 'Ruby Red' grapefruit were formed in the haploid. These findings indicate that this haploid was of maternal origin. To date, Citrus haploids obtained from inter-polyploid hybridization (Oiyama and Kobayashi, 1993) and in vitro pollination (Germana and Chiancone, 2001) have also been of maternal origin. Therefore, gynogenesis might be facilitated by the stimulation of pollination in several citrus cultivars, although low frequency generation in all cases.

Flow cytometry analysis revealed that the fluorescence intensity of the haploid was half of those of leaves, sepals, petals, and filaments of 'Banpeiyu' pummelo (Fig. 4). Furthermore, chromosome observation of the young leaves of several stems revealed that the chromosome number of the haploid was 9 (Fig. 1C). These results demonstrated that the ploidy level of haploid was maintained for 7 years. Generally, it is easy to double the number of chromosomes of haploids, and therefore the maintenance of haploid cells is extremely difficult (Wenzel et al., 1976). In Citrus plants and their relatives, diploid and mixoploid plantlets have been produced from anther culture (Chen et al., 1980; Hidaka, 1984; Hidaka et al., 1982; Wenzel et al., 1976). Yamamoto and Tominaga (2002) also reported that diploid tissue occurred as a result of a part of haploid clementine. In the present study, the haploidy was maintained in all of the several tissues and organs studied. It is likely that the genotype of Citrus species may be an important factor for maintaining the chromosomes of haploid.

The morphological characteristics of the haploid were compared with those of 'Banpeiyu' pummelo. The haploid had significantly small leaves and yet a large shape index, as compared to those of 'Banpeiyu' pummelo (Table 1, Fig. 5A). The leaf weight per unit area of the haploid $\left(22.0 \mathrm{mg} \cdot \mathrm{cm}^{-2}\right)$ was significantly lighter than that of 'Banpeiyu' pummelo $\left(34.8 \mathrm{mg} \cdot \mathrm{cm}^{-2}\right)$. The stomata size of the haploid was also significantly smaller than that of 'Banpeiyu' pummelo. The flowers of the haploid were about half the size of those of 'Banpeiyu' pummelo (Table 2, Fig. 5B). In addition, the haploid had a significantly reduced number of stamens and ovules compared with those of 'Banpeiyu' pummelo. In the flowers of the haploid, abnormalities such as the adhesion of pistils and stamens were observed. The haploid 

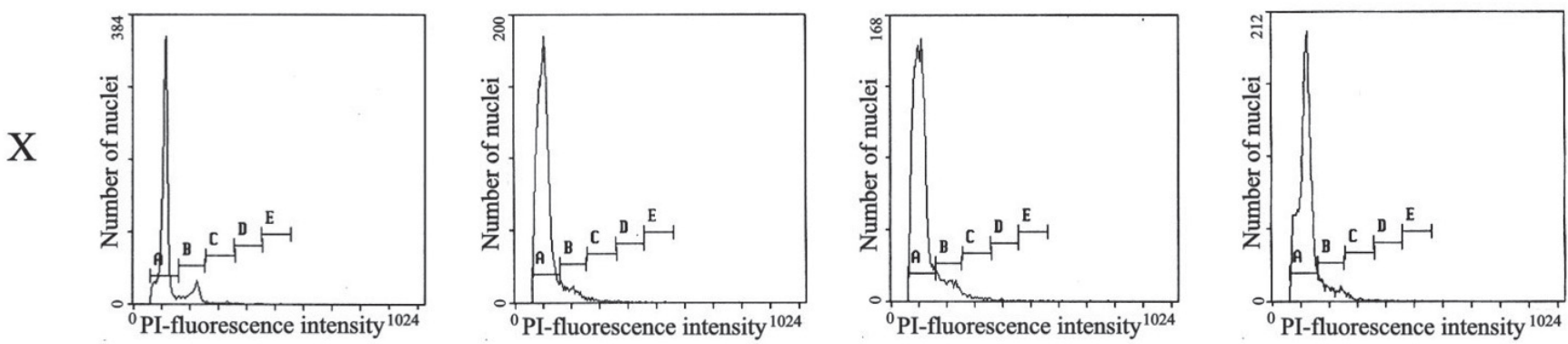

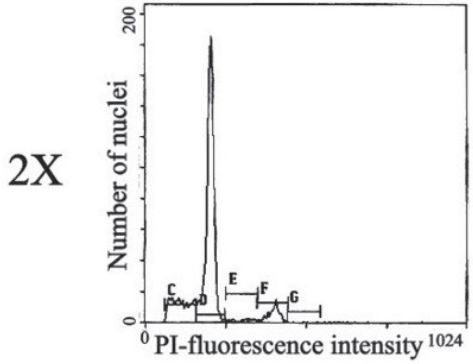

Leaf

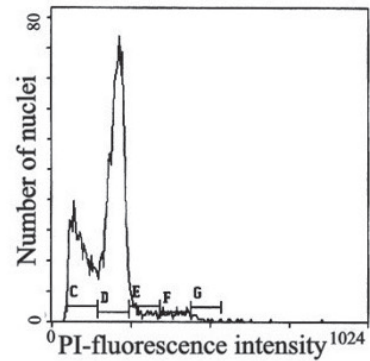

Sepal

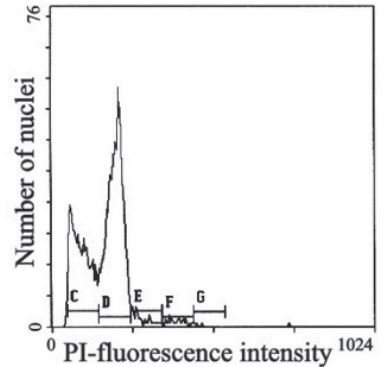

Petal

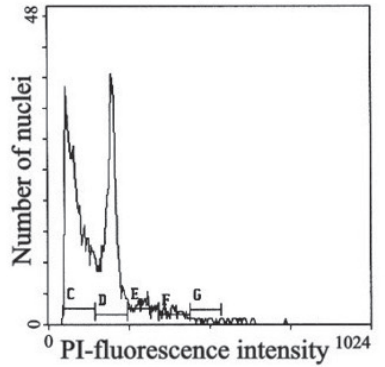

Filament

Fig. 4. Flow cytometry analysis of leaves, sepals, petals, and filaments in the haploid and 'Banpeiyu' pummelo.

Table 1.Comparison of morphological characteristics of leaf in the haploid and 'Banpeiyu' pummelo.

\begin{tabular}{|c|c|c|c|c|c|c|c|c|c|}
\hline \multirow{2}{*}{ Strains } & \multicolumn{2}{|c|}{ Leaf blade $(\mathrm{mm})$} & \multirow{2}{*}{$\begin{array}{l}\text { Shape index } \\
\text { of leaf blade }\end{array}$} & \multicolumn{2}{|c|}{ Wing leaf $(\mathrm{mm})$} & \multirow{2}{*}{$\begin{array}{l}\text { Shape index } \\
\text { of wing leaf }\end{array}$} & \multirow{2}{*}{$\begin{array}{l}\text { Leaf weight } \\
\left(\mathrm{mg} / \mathrm{cm}^{2}\right)\end{array}$} & \multicolumn{2}{|c|}{ Stomata $(\mu \mathrm{m})$} \\
\hline & Length & Width & & Length & Width & & & Length & Width \\
\hline Haploid & $108.6 b^{2}$ & $54.1 \mathrm{~b}$ & $2.0 \mathrm{a}$ & $24.6 b$ & 16.1 NS & $1.7 \mathrm{NS}$ & $22.0 \mathrm{~b}$ & $17.0 \mathrm{~b}$ & $15.1 \mathrm{~b}$ \\
\hline 'Banpeiyu' pummelo & $143.8 \mathrm{a}$ & $82.9 \mathrm{a}$ & $1.7 \mathrm{~b}$ & $31.2 \mathrm{a}$ & 22.1 & 1.5 & $34.8 \mathrm{a}$ & $22.2 \mathrm{a}$ & $19.6 \mathrm{a}$ \\
\hline
\end{tabular}

${ }^{2}$ Mean separation by Tukey's multiple range test, $\mathrm{P}=0.05$.

$\mathrm{y}_{\text {Length }}$ of leaf blade/Width of leaf blade.

${ }^{x}$ Length of wing leaf/Width of wing leaf.
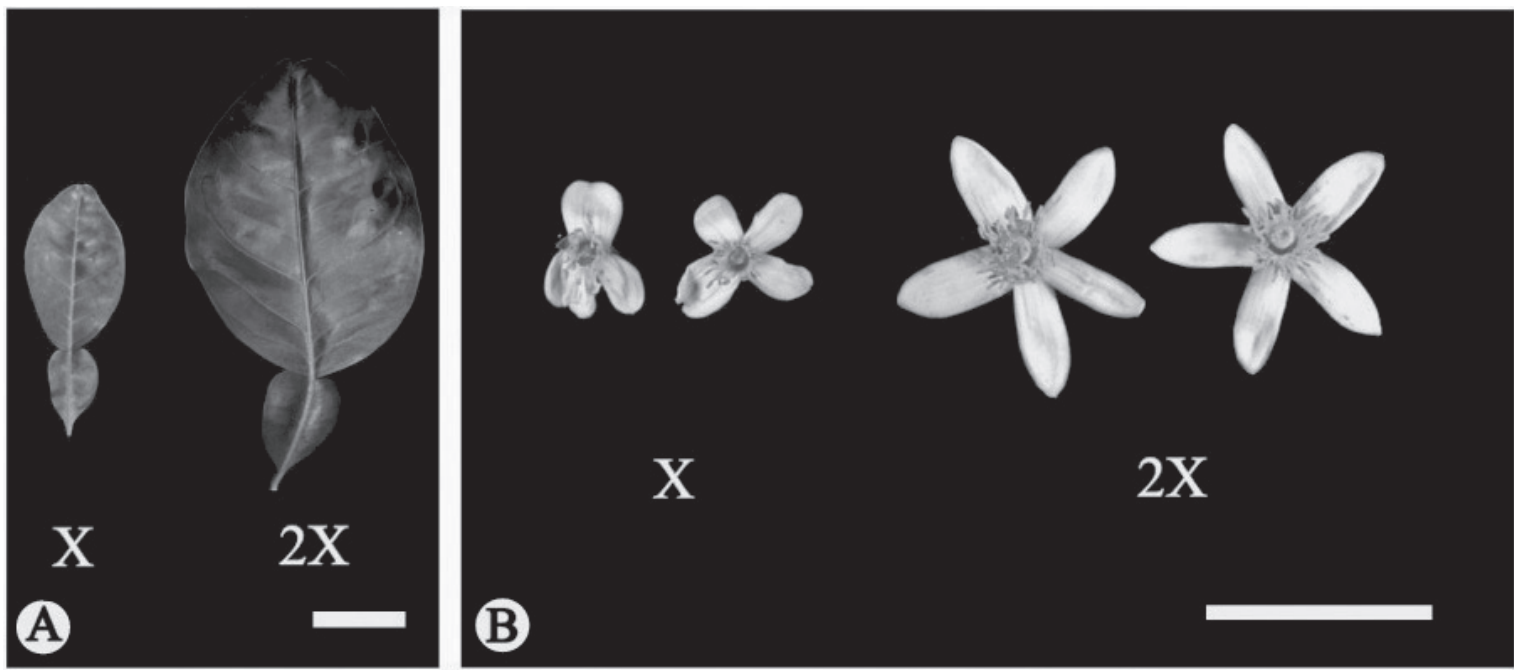

Fig. 5. The morphological characteristics of leaves $(\mathbf{A})$ and flowers $(\mathbf{B})$ in the haploid and 'Banpeiyu' pummelo $(\mathrm{bar}=5 \mathrm{~cm})$. 
Table 2.Comparison of morphological characteristics of flower in the haploid and 'Banpeiyu' pummelo.

\begin{tabular}{|c|c|c|c|c|c|c|c|c|c|c|}
\hline \multirow{2}{*}{ Strains } & \multirow{2}{*}{$\begin{array}{l}\text { Diameter } \\
(\mathrm{mm})\end{array}$} & \multirow{2}{*}{$\begin{array}{l}\text { No. of } \\
\text { petal }\end{array}$} & \multicolumn{2}{|c|}{ Petal (mm) } & \multirow{2}{*}{$\begin{array}{l}\text { No. of } \\
\text { pistil }\end{array}$} & \multirow{2}{*}{$\begin{array}{l}\text { Length of } \\
\text { pistil } \\
\text { (mm) }\end{array}$} & \multicolumn{2}{|c|}{ Ovary $(\mathrm{mm})$} & \multirow{2}{*}{$\begin{array}{l}\text { No. of } \\
\text { ovule }\end{array}$} & \multirow{2}{*}{$\begin{array}{l}\text { No. of } \\
\text { stamen }\end{array}$} \\
\hline & & & Length & Width & & & Length & Width & & \\
\hline Haploid & $30.7 b^{2}$ & $4.1 \mathrm{~b}$ & $17.3 \mathrm{~b}$ & $10.9 \mathrm{~b}$ & $1.0 \mathrm{NS}$ & $11.0 \mathrm{~b}$ & $4.2 \mathrm{~b}$ & $4.0 \mathrm{~b}$ & $66.8 \mathrm{~b}$ & $29.0 \mathrm{~b}$ \\
\hline 'Banpeiyu' pummelo & $56.9 \mathrm{a}$ & $4.8 \mathrm{a}$ & $36.3 \mathrm{a}$ & $24.3 \mathrm{a}$ & 1.0 & $20.6 \mathrm{a}$ & $8.6 \mathrm{a}$ & $9.5 \mathrm{a}$ & $213.0 \mathrm{a}$ & $43.1 \mathrm{a}$ \\
\hline
\end{tabular}

${ }^{2}$ Mean separation by Tukey's multiple range test, $\mathrm{P}=0.05$.

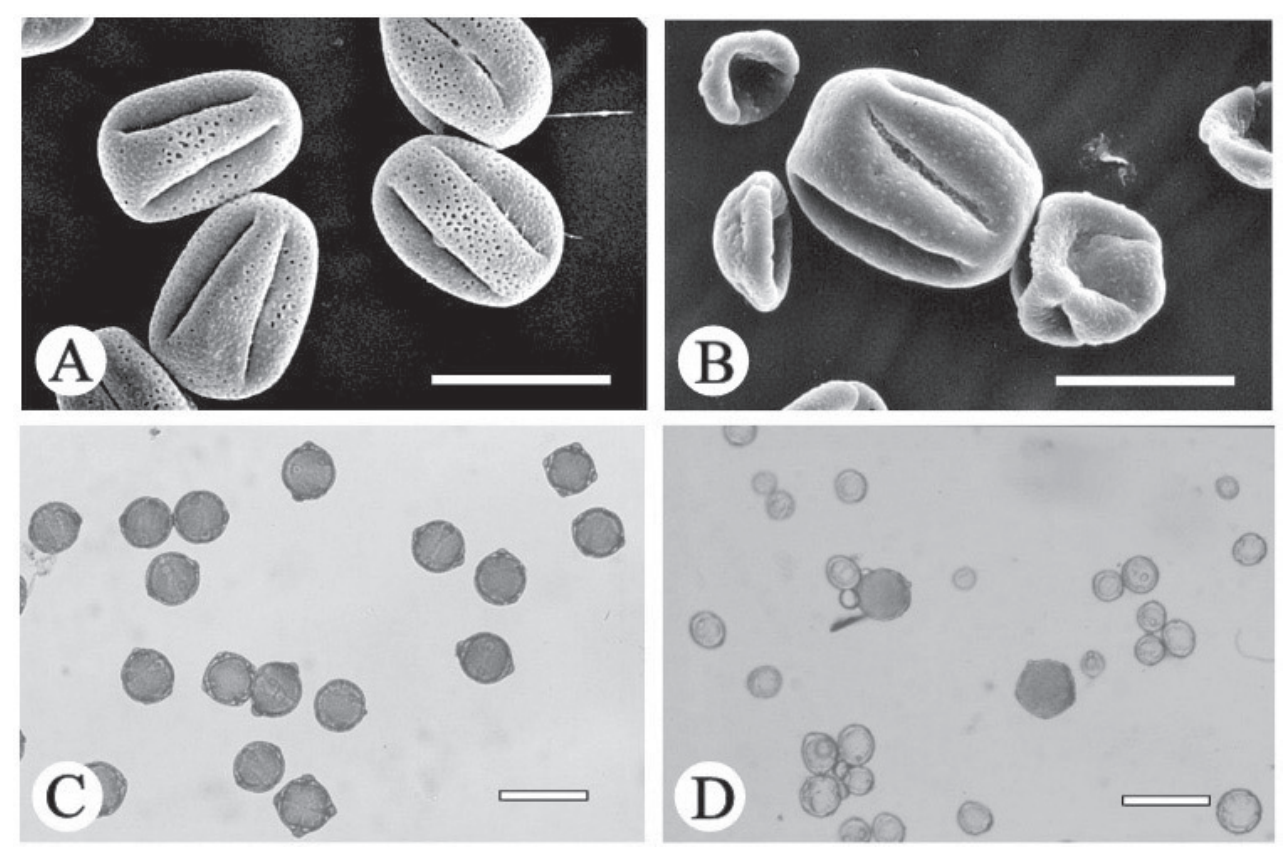

Fig. 6. The morphological characteristics of the pollen grains in the haploid and 'Banpeiyu' pummelo. Scanning electron micrographs of pollen grains of 'Banpeiyu' pummelo $(\mathbf{A})$ and the haploid $(\mathbf{B})(\mathrm{bar}=30 \mu \mathrm{m})$. Pollen grains of 'Banpeiyu' pummelo $(\mathbf{C})$ and the haploid $(\mathbf{D})$ stained by $1 \%$ acetocarmine (bar $=50 \mu \mathrm{m})$.

Table 3.Comparison of morphological characteristics of pollen grains in the haploid and 'Banpeiyu' pummelo.

\begin{tabular}{|c|c|c|c|c|c|c|}
\hline \multirow{2}{*}{ Strains } & \multirow{2}{*}{$\begin{array}{l}\text { No. of pollen grain } \\
\text { per anther }\end{array}$} & \multicolumn{2}{|c|}{ Pollen grain $(\mu \mathrm{m})$} & \multirow{2}{*}{$\begin{array}{l}\text { Shape index of } \\
\text { pollen grain }\end{array}$} & \multicolumn{2}{|c|}{ Pollen fertility $(\%)$} \\
\hline & & Length & Width & & Stainability & In vitro germination \\
\hline Haploid & $8825 b^{2}$ & $25.4 \mathrm{~b}$ & $22.0 \mathrm{~b}$ & $1.2 \mathrm{~b}$ & $1.6 \mathrm{~b}$ & $0.4 \mathrm{~b}$ \\
\hline 'Banpeiyu' pummelo & $63097 \mathrm{a}$ & $37.3 \mathrm{a}$ & $26.3 a$ & $1.4 \mathrm{a}$ & $98.0 \mathrm{a}$ & $88.6 \mathrm{a}$ \\
\hline
\end{tabular}

${ }^{2}$ Mean separation by Tukey's multiple range test, $\mathrm{P}=0.05$.

${ }^{y_{L e n g t h}}$ of pollen grain/Width of pollen grain.

had a remarkably reduced number of the pollen grains per anther $(\approx 9000)$ compared with that of 'Banpeiyu' pummelo $(\approx 63,000)$. Moreover, the average size of the pollen grains from the haploid was smaller than that of the grains from 'Banpeiyu' pummelo. Our SEM observations revealed that most of the pollen grains of 'Banpeiyu' pummelo were elliptical in shape (Fig. 6A), whereas the shape of the haploid grains had severely depressed morphology; these pollen grains were thus presumed to be sterile, although a few normally shaped pollen grains from the haploid were also observed (Fig. 6B).

Haploids of fruit crops show generally poor growth and their leaves and flowers tend to be smaller than those of diploid plants (Chalak and Legave, 1996; Dweikat and Lyrene, 1990; Horfer and
Lespinasse, 1996; Pooler and Scorza, 1995; Toyama, 1974; Zhang and Lespinasse, 1991). In Citrus species, haploids of clementine and 'Lee' show dwarf growth habit and rosette morphology in the early stages of growth (Oiyama and Kobayashi, 1993). Although the flowering of haploids has rarely been reported for fruit crops, the morphology of haploid flowers has been reported in Prunus persica Batsch, in which the haploid had smaller flowers than the diploid, and the haploid shed very few pollen grains (Pooler and Scorza, 1995). In the present study, the haploid of 'Banpeiyu' pummelo also showed a morphology that was similar to that of the haploids of other fruit crops.

The fertility of the pollen grains was evaluated by stainability with acetocarmine and in vitro germination (Table 3). 'Banpeiyu' 


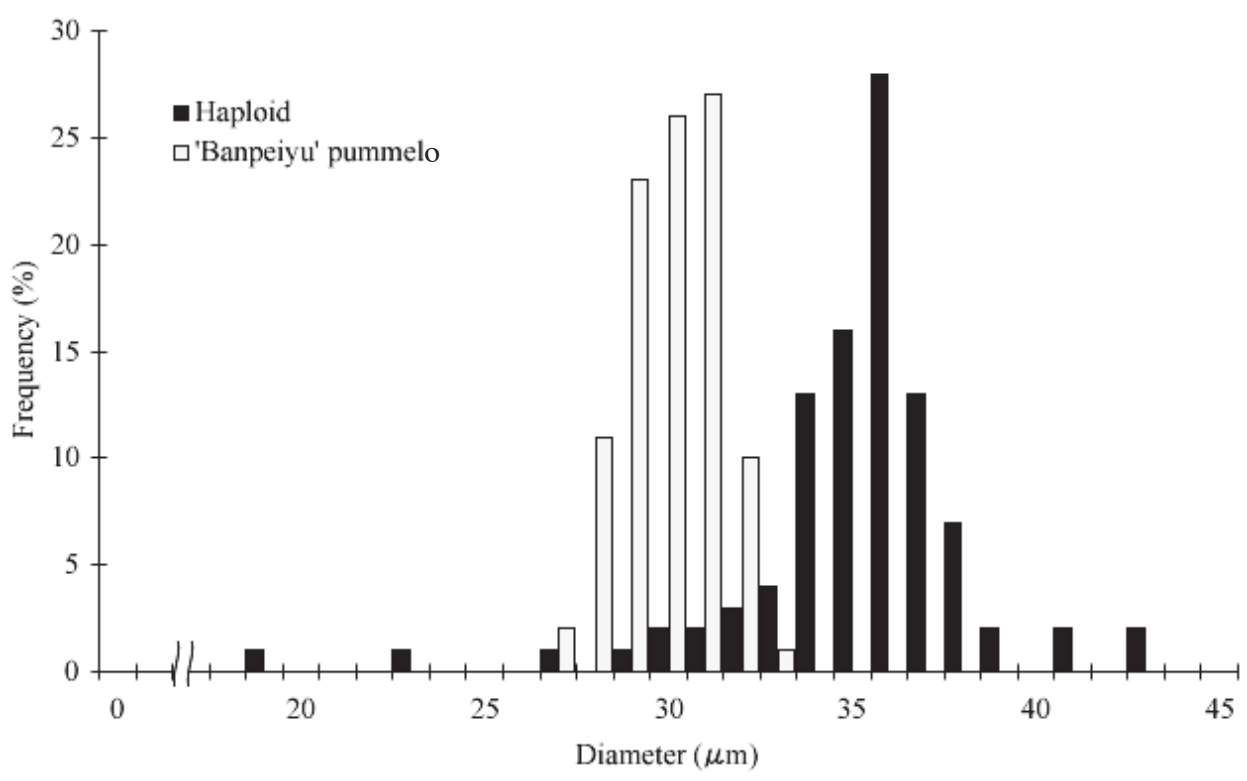

Fig. 7. Comparison of the diameter of the fertile pollen grains in the haploid and 'Banpeiyu' pummelo.

Hesse, 1971; Pooler and Scorza, 1995; Veilleux, 1985; Yan et al., 2000; Zagorcheva et al., 1987). In particular, the haploid of C. апnиит was shown to have relatively high pollen fertility $(10 \%)$, as assessed by acetocarmine staining (Yan et al., 2000). In P. persica and $C$. annuum, it has also been reported that the fertile pollen grains of the haploids was of equal size to those of the diploid mother parent (Pooler and Scorza, 1995; Yan et al., 2000). However, in the present study, the fertile pollen grains of the haploid were larger than those of the diploid, although the fertility of the pollen remained quite low. To account for the production of these large fertile pollen grains, detailed cytological observation, especially at meiosis, remain necessary.

In order to evaluate the reproductive potential of male and female gametes of the haploid, crosses with diploid
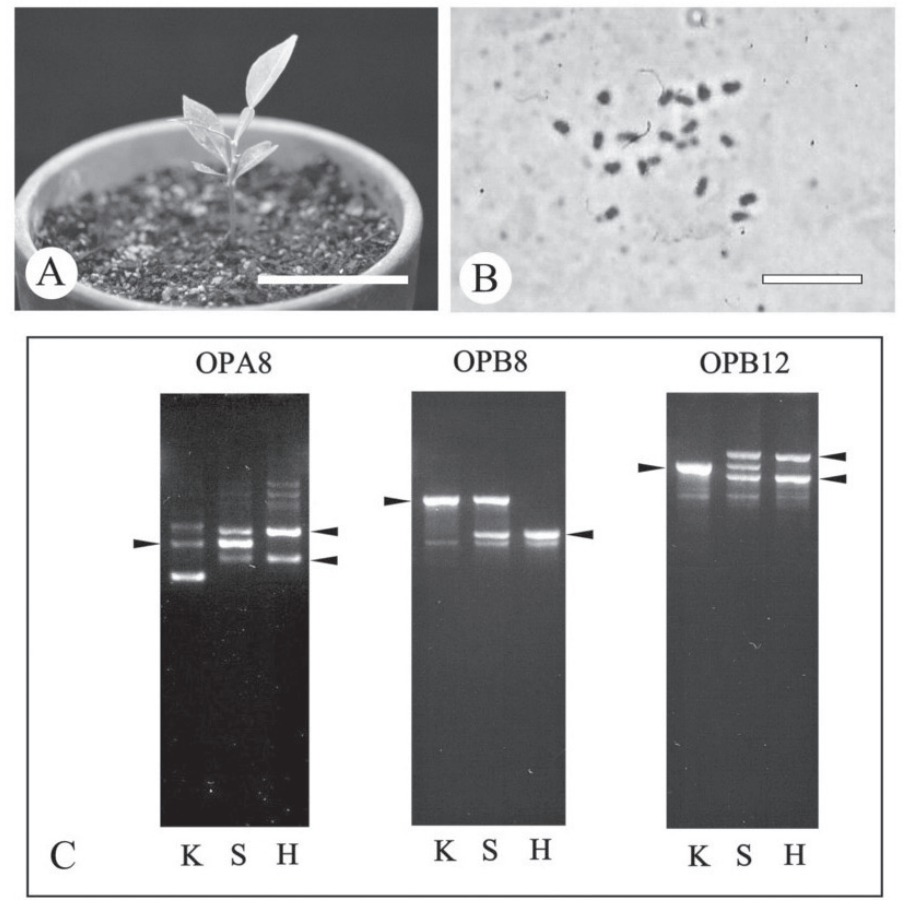

Fig. 8. Analysis of seedling No.1 obtained from the cross between 'Kiyomi' tangor and the haploid; $\mathrm{A}=$ seedling No.1 4 months after germination $(\mathrm{bar}=5 \mathrm{~cm})$; $\mathrm{B}=$ chromosome number $2 \mathrm{n}=2 \mathrm{X}=18(\mathrm{bar}=10 \mu \mathrm{m}) ; \mathrm{C}=\mathrm{RAPD}$ analysis of 'Kiyomi' tangor (K), seedling No.1 (S), and the haploid (H). Arrows indicate the bands specific to each parent.

pummelo showed $98.0 \%$ stainability and $88.6 \%$ pollen germination rate, respectively (Fig. 6C), whereas those of the haploid were only $1.6 \%$ and $0.4 \%$, respectively (Fig. 6D). Furthermore, the diameter of the fertile pollen grains of the haploid was slightly larger than that of 'Banpeiyu' pummelo grains (Fig. 7); the measurements were $\approx 30 \mu \mathrm{m}$ in 'Banpeiyu' pummelo and $\approx 35 \mu \mathrm{m}$ in the haploid.

It has been reported that haploids in some species such as Brassica napus L., Glycine max Merrill, P. persica, Lycopersicon esculentum Mill., Cucumis ficifolius A. Rich, and Capsicum annиum L. could form fertile pollen grains (Crane et al., 1982; cultivars have been carried out. When 'Kitou-Yuzu' was pollinated to the haploid used as the seed parent, no fruit set was observed. However, when 'Kiyomi' tangor was pollinated with the pollen of the haploid, the fruits were set, and some seeds were obtained from the fruits as well. When these seeds were transferred onto moist vermiculite, 11 normal seedlings were produced 4 months after the transfer (Fig. 8A). Flow cytometry analysis of all those seedlings showed that their fluorescence intensity coincided with that of the diploid control. The chromosome count of immature leaflets revealed that all of the seedlings had 18 chromosomes (Fig. 8B). All of the seedlings also had large wing leaves, which is the typical morphology of 'Banpeiyu' pummelo (Fig. 8A). Furthermore, the hybridity of seedling No. 1 was confirmed using RAPD analysis by comparison with both parents (Fig. 8C). Among the primers tested, OPA8, OPB8, and OPB12 were found to be suitable for discrimination between 'Kiyomi' tangor and the haploid. Seedling No. 1 had fragments specific for both parents. These results suggest that the seedlings were diploid hybrids between 'Kiyomi' tangor and the haploid, and that fertilization had indeed occurred between the normal eggs of 'Kiyomi' tangor and unreduced pollen grains.

In C. annuит, Yan et al. (2000) revealed that the mechanism of fertility restitution in haploid plants was due to first division restitution (FDR) at meiosis. Similarly, fertile $1 \mathrm{n}$ pollen was produced by FDR, which has also been reported in the haploid of $B$. napus and L.esculentum. (Veilleux, 1985). It is therefore possible that the unreduced pollen grains of the haploid of 'Banpeiyu' pummelo $(n=9)$ were also the result of the FDR mechanism.

In conclusion, we confirmed here that the haploid produced by the cross between 'Banpeiyu' pummelo and 'Ruby Red' grapefruit (Toolapong et al., 1996) was derived from the female gamete of 'Banpeiyu' pummelo. Furthermore, the haploid produced slightly fertile pollen grains, and diploid hybrid progenies were obtained from the cross between 'Kiyomi' tangor and the haploid. In a future study, this haploid will be used for breeding as the male parent without chromosome doubling, and for the analysis of favorable genes (e.g., self-incompatibility). Several studies are still needed to fully understand haploid induction and to elucidate the fertility restitution mechanism in these plants. 


\section{Literature Cited}

Bajaj, Y.P.S. 1990. In vitro production of haploids and their use in cell genetics and plant breeding, p. 1-44. In: Y.P.S. Bajaj (ed.). Haploids in crop improvement. Biotechnology in agriculture and forestry, vol. 12. Springer-Verlag, New York.

Chalak, L. and J.M. Legave. 1996. Oryzalin combined with adventitious regeneration for an efficient chromosome doubling of trihaploid kiwifruit. Plant Cell Rpt. 16:97-100.

Chen, Z., M. Wang, and H. Liao. 1980. The induction of citrus pollen plants in artificial media. Acta Genet. Sinica 7:189-191.

Crane, C.F., W.D. Beversdorf, and E.T. Bingham. 1982. Chromosome pairing and associations at meiosis in haploid soybean (Glycine max). Can. J. Genet. Cytol. 24:293-300.

Doyle, J. and J.L. Doyle. 1987. A rapid DNA isolation procedure for small quantities fresh leaf tissue. Phytochem. Bul. 19:11-15.

Dweikat, I.M. and P.M. Lyrene. 1990. Twin seedlings and haploids in blueberry (Vaccinium spp.). J. Hered. 81:198-200.

Fukui, K. 1996. Plant chromosome at mitosis, p. 1-17. In: K. Fukui and S. Nakayama (eds.). Plant choromosome. Laboratory methods. CRC Press, Boca Raton, Fla.

Germana, M.A. and B. Chiancone. 2001. Gynogenetic haploids of Citrus after in vitro pollination with triploid pollen grains. Plant Cell Tissue Organ Cult. 66:59-66.

Germana, M.A. and B. Chiancone. 2003. Improvement of Citrus clementina Hort. ex Tan. microspore-derived embryoid induction and regeneration. Plant Cell Rpt. 22:181-187.

Harusaki K., D. Kokuryo, H. Kunitake, and H. Komatsu. 2000. Determination of ploidy level of Citrus species using flow cytometry. Proc. School Agr. Kyushu Tokai Univ. 19:45-52.

Hesse, C.O. 1971. Monoploid peaches, Prunus persica Bastsch: Description and meiotic analysis. J. Amer. Soc. Hort. Sci. 96:326-330.

Hidaka, T., Y. Yamada, and T. Shichijo. 1979. In vitro differentiation of haploid plants by anther culture in Poncirus trifoliata (L.) Raf. Jpn. J. Breeding 29:248-254.

Hidaka,T., Y. Yamada, and T. Shichijo. 1982. Plantlet formation by anther culture in Citrus aurantium L. Jpn. J. Breeding 32:247-252.

Hidaka, T. 1984. Induction of plantlets from anthers of 'Trovita' orange (Citrus sinensis Osbeck). J. Jpn. Soc. Hort. Sci. 53:1-5.

Hirai, M., I. Kozaki, and I. Kajiura. 1986. Isozyme analysis and phylogenic relationship of Citrus. Jpn. J. Breeding 36:377-389.

Horfer, M. and Y. Lespinasse. 1996. Haploidy in apple, p. 261-276. In: S.M. Jain, S.K. Sopory, and R.E. Veilleux (eds.). In vitro haploid production in higher plants, vol. 3. Kluwer, Dordrecht.
Karasawa, K. 1971. On the occurrence of haploid seedlings in Citrus natsudaidai Hayata. Bul. Sakushingakuin Junior College for Women $1: 1-2$.

Ochatt, S.J. and Y.X. Zhang. 1996. In vitro haploidization of fruit trees, p. 193-210. In: S.M. Jain, S.K. Sopory, and R.E. Veilleux (eds.). In vitro haploid production in higher plants, Vol 3. Kluwer, Dordrecht.

Oiyama, I. and S. Kobayashi. 1993. Haploids obtained from diploid $\times$ triploid cross of Citrus. J. Jpn. Soc. Hort. Sci. 62:89-93.

Pooler, M. and R. Scorza. 1995. Occurrence of viable eggs in haploid peach. Fruit Var. J. 49:239-241.

Toolapong, P., H. Komatsu, and M. Iwamasa. 1996. Triploids and haploid progenies derived from small seeds of 'Banpeiyu' pummelo, crossed with 'Ruby Red' grapefruit. J. Jpn. Soc. Hort. Sci. 65:255-260.

Toyama, T.K. 1974. Haploidy in peach. HortScience 9:187-188.

Veilleux, R. 1985. Diploid and polyploid gametes in crop plants: Mechanisms of formation and utilization in plant breeding. Plant Breeding Rev. 3:253-288.

Wan, Y., J.F. Petolino, and J.M. Widholm. 1989. Efficient production of doubled haploid plants through colchicine treatment of anther-derived maize callus. Theor. Appl. Genet. 77:889-892.

Wan, Y., D.R. Duncan, A.L. Rayburn, J.F. Petolino, and J.M. Widholm. 1991. The use of antimicrotubule herbicides for production of doubled haploid plants from anther-derived maize callus. Theor. Appl. Genet. 81:205-211.

Wan, Y. and J.M. Widholm. 1995. Effect of chromosome-doubling agents on somaclonal variation in the progeny of doubled-haploids in maize. Plant Breeding 114:253-255.

Wenzel, G., F. Hoffmann, and E. Thomas. 1976. Heterozygous microspore-derived plants in rye. Theor. Appl. Genet. 48:205-208.

Williams, J.G.K.,A.R. Kubelik, K.J. Lival, J.A. Rafalski, and S.V. Tingey. 1990. DNA polymorphisms amplified by arbitrary primers are useful as genetic markers. Nucl. Acids Res. 18:6531-6535.

Yamamoto, M. and S. Tominaga. 2002. A haploid-diploid periclinal chimera obtained from haploid clementine (Citrus clementina). J. Jpn. Soc. Hort. Sci. 71 (suppl. 2):314.

Yan, L.Y., X.Z. Zhang, and G.J. Liu. 2000. Occurrence of unreduced gametes and ploidy restoration in haploid Capsicum annuum L. J. Hort. Sci. Biotechnol. 75:195-197.

Zagorcheva, L., M. Aleksandrova, and T. Kichukova. 1987. Meiosis in haploid of Cucumis ficifolius A. Rich. Genetica i Selektsiya 20:269-271.

Zhang, Y.X. and Y. Lespinasse. 1991. Pollination with gamma-irradiated pollen and development of fruits, seeds and parthenogenetic plants in apple. Euphytica 54:101-109. 